\title{
The Mediating Role of Job Satisfaction on the Effect of Emotional Intelligence of Nurses in Public Hospitals in Gaza Strip on Job Burnout
}

\author{
Ahmed Qeshta $^{1^{*}}$ Siti Aida Samikon ${ }^{2}$ \\ 1. PhD Student, Post Graduate Centre, Limkokwing University, 63000 Cyberjaya, Selangor, Malaysia \\ 2. Lecturer, Post Graduate Centre, Limkokwing University, 63000 Cyberjaya, Selangor, Malaysia \\ E-mail: akq90@hotmail.com
}

\begin{abstract}
Service employees, particularly nurses need to be professional in dealing with clients and maintaining their emotion. Moreover, they should have a sufficient level of knowledge and experience in order to enhance the healthcare service without any damage in their emotion and the level of their job satisfaction. This study aims to examine the impact of emotional intelligence on job burnout mediated by job satisfaction. The research model has six constructs, which are: self-emotion appraisal, others' emotion appraisal, use of emotion, regulation of emotion, job satisfaction and job burnout. Respondents in this study are nurses in public hospitals in Gaza strip. A self-administered questionnaire was used to collect data. The sample size for this study is 450 respondents. The validity and reliability of scales will be examined using Average Variance Extracted (AVE), AVE square root, Fornell and Larcker's (1981) measure of composite reliability and Cronbach's alpha. The findings of this study will provide invaluable input to all healthcare providers in understanding the main role and importance of service employee's emotion status in providing a superior service to patients in the unstable environment such as Gaza strip by managing his/her emotions during the interaction process with patients to avoid any damage in their emotion status.
\end{abstract}

Keywords: Emotions, emotional intelligence, job satisfaction, job burnout.

DOI: $10.7176 / \mathrm{EJBM} / 13-12-08$

Publication date:June $30^{\text {th }} 2021$

\section{Introduction}

In service areas, employees and workers are always in contact with their clients directly or indirectly (Salmi and Kinnunen, 2015). Davenport (2013) stated that staffs try to perform their work in a proper way and they might have a small choice to show off positive emotions at their profession. According to Preksha and Maheshwari (2018), healthcare workers, especially nurses are more likely to experience higher levels of stress, anxiety and depression; they also suffer the consequent psychosocial and biological effects of stress more than people in other professions. Nabirye et al. (2011) stated that healthcare workers in hospitals suffer from depression more than workers in other work fields. Thus, when nurses make a contact with patients, emotions, gestures, and postures of employees have a boundless importance so always there is a stress on staff from the administration to learn, train, and apply the learned emotions while dealing with clients (Salmi and Kinnunen, 2015). Ministry of Health (2019) stated that 2364 nurses are working in public hospitals in Gaza strip, which is distributed over 13 public hospitals. In the past, researchers ignored emotions role in their studies of organizational behavior (Arvey et al., 1998). They considered workplace as a rational environment where employees' emotions have no effect (Putnam and Mumby, 1993). This view has been changed by researchers because they found that employee's emotions in the workplace affect individual and organizational outcomes (Arvey et al. 1998).

\section{Emotional Intelligence}

The concept of Emotional Intelligence was first introduced nearly a century ago. The published literature has acknowledged that the work conducted by Thorndike (1920) on social intelligence was the earliest work on emotional intelligence (Bar-On 2006; Gardner 1983). Gardner (1983) proposed the presence of different types of intelligences in individuals including the concepts of emotional intelligence and intrapersonal intelligence. Emotional Intelligence is the ability of knowing, understanding, managing and reacting to emotions among others. Intrapersonal Intelligence is the ability of knowing, understanding, managing and responding to one's 
own feelings and emotions. Gardner (1983) thought that these types of intelligences are as important as the type of intelligence typically measured by intelligence quotient (Petrides 2011). Furthermore, emotional intelligence term was coined for the first time by Salovey and Mayer (1990). This concept was given currency by Daniel Goleman in his book, emotional intelligence, published in 1995. Goleman (1995) claimed that Emotional Intelligence could be more powerful than Intelligence Quotient, caught the attention of scholars and made his book the bestseller of the time (Goleman 1995). Many researchers started to develop models and theories of emotional intelligence as it received wider acceptance from the scholarly community. In addition, the research literature on emotional intelligence has categorized these models into ability and trait/mixed models. The ability emotional intelligence models concentrate on mental abilities which enable people to use emotions-laden information with the aim of cognitive processing. That is, the ability models conceptualize emotional intelligence as a set of mental abilities for solving emotion-related problems. The mixed emotional intelligence models are the combination of mental abilities and personality traits such as enthusiasm, optimism, selfconfidence, etc. (Daus and Ashkanasy 2003; Fernandez-Berrocal and Ruiz 2008). Salovey and Mayer (1990) defined emotional intelligence as: the ability to monitor one's own and others' feelings and emotions, to discriminate among them, and to use this information to guide one's thinking and actions. Mayer and Salovey divided emotional intelligence skills and abilities into four areas and called it as four-branch model which is conceptually arranged from more basic psychological processes to higher psychologically integrated processes: Perception and Expression of Emotion, Emotional facilitation of thinking, Understanding emotions and Regulating/Managing emotions (Mayer and Salovey 1997). In 1998, Goleman introduced the Emotional Competence Framework, which grouped emotional intelligence competencies into two major categories: Personal Competencies and Social Competencies. Each of these, in turn, contains several domains or clusters (Goleman 1998). The Goleman's model considered emotional intelligence as an array of emotional and social competencies and is known as competency model of emotional intelligence. It has been categorized as a mixed model which is specifically designed for workplace applications (Mayer, Salovey and Caruso 2000).

According to Bar-On (2006), emotional intelligence is composed of several intrapersonal and interpersonal competencies, skills and facilitators that jointly determine effective human behavior. Therefore, he labeled this concept as Emotional-Social Intelligence. The emotional and social competencies in this conceptualization are grouped into five key components each with a number of other closely related sub-competencies and skills (BarOn 2006). Mixed models of emotional intelligence (e.g. Goleman's model and Bar-On's model) are more suitable for work place applications to study leadership traits, managerial skills and organizational commitment etc. of professionals. Whereas, the ability models (e.g. Mayer and Salovey's model) are more suitable for studying the student population with respect to their academic characteristics.

\section{Job Satisfaction and Job Burnout}

The most used meaning of job satisfaction in organizational research is that of Locke (1976), who depicted job satisfaction as a pleasurable or positive emotional state resulting from the appraisal of one's job or job exercises. According to Weiss (2002), Cognitive and effective of job dissatisfaction are probably going to pervade and influence an individual's imagination from the minute he or she wakes to the minute the individual returns home from work.

The notion of burnout was firstly coined by Freudenberger (1974) as exhaustion, disappointment, loss of power and energy as a result of exhaustion or overloading in person's internal resources and energy as an outcome of unfulfilled desires. Amongst physical, behavioral and psychological problems affected by organizational stress, some diverse responses were noticed in 1970s and they were denominated as burnout (Freudenberger, 1974). With a view to reveal levels of burnout, Burnout Inventory created by Maslach (1981) was used by this study. According to Maslach (1981), burnout is defined as the condition which is experienced individually, is resulting from working in atmospheres with intense emotional anticipations for a long term, and is accompanied by symptoms such as desperation, disappointment, physical exhaustion, hopelessness, increase of negative behavior toward work, workplace, colleagues and life (Çokluk, 2000).

\section{Theoretical and Conceptual Framework}

The main goal of the conceptual framework of this study is to examine the effect of emotional intelligence on job satisfaction, which in return, affect job burnout in nurse in public hospitals in Gaza strip. This study is primarily based on well-established models and theories, which are employed to develop the framework of this study. this study relies on the ability model (Salovey and Mayer 1990) and affective theory, which states that emotions are the one contribute to defining work satisfaction to examine the relationship between emotional intelligence and job satisfaction (Sy et al. 2006). In addition, this study relies on job demand-control (JDC) theory to examine the relationship between job satisfaction and job burnout. 
Figure 1 illustrates the research framework for this study, where the independent variables are self-emotion appraisal, others' emotion appraisal, use of emotion and regulation of emotion, job satisfaction as a mediator variable and job burnout as the dependent variable.

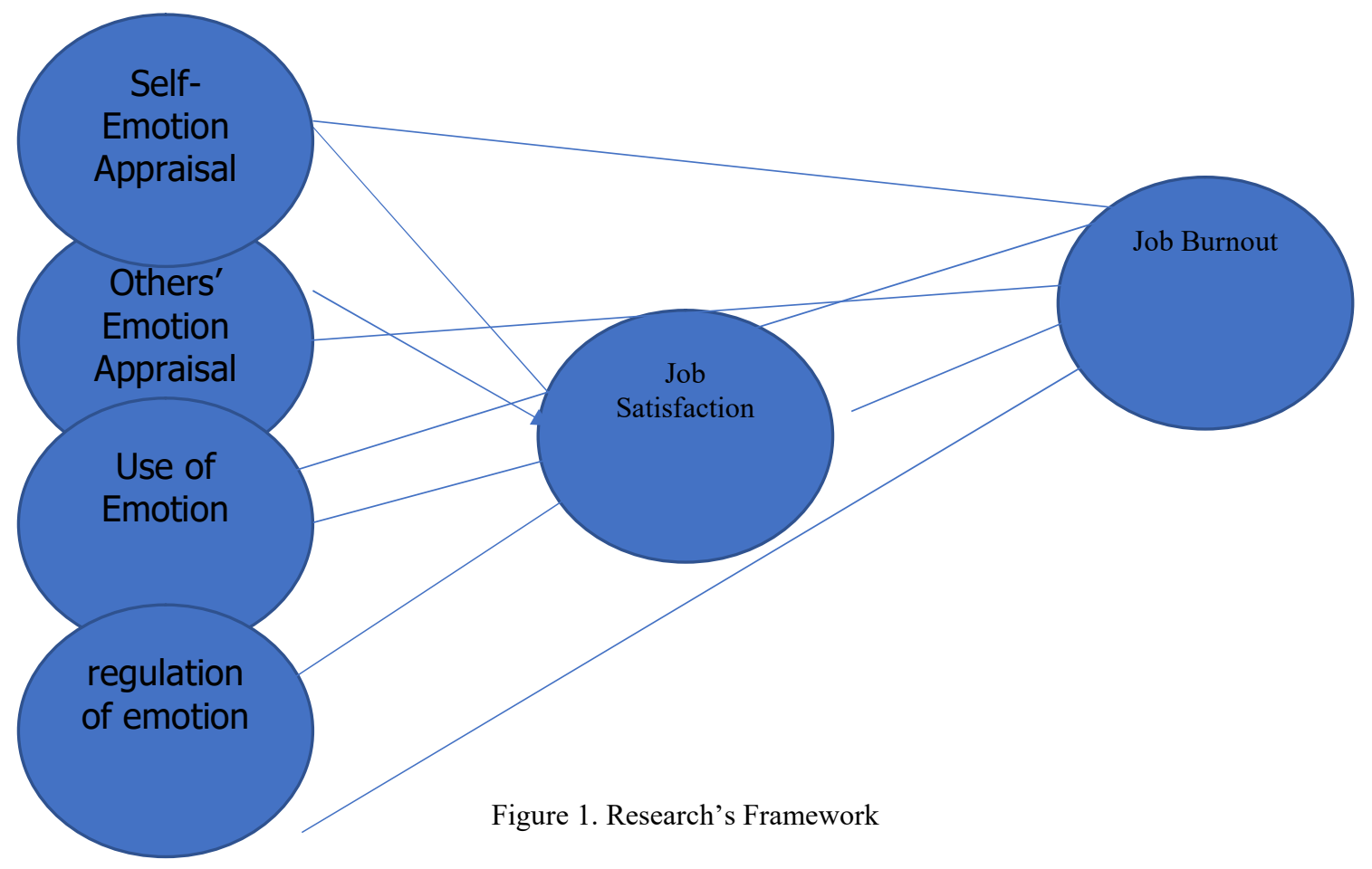

Various researches have been conducted on association between Employees' emotional intelligence and level of job satisfaction in their working environment (Asvio et al. 2019; Liu 2016). Tagoe and Quarshie (2016) produced significant amount of evidences pertaining to affirmative alliance between higher emotional intelligence and job satisfaction.

\section{Hypothesis 1:}

1a: Emotional intelligence is positively related to job satisfaction.

\section{2b: Emotional intelligence is negatively related to job burnout.}

As mentioned earlier, employees with high level of emotional intelligence are capable to regulate their emotions, which in return make an influence on their level of psychological well-being and job satisfaction (Gholipour and Einolahzadeh, 2017; Zhang, et al., 2018). According to Laborde et al. (2016), emotional intelligence affects job satisfaction positively. In addition, job satisfaction has a negative impact on job burnout (Peng, et al., 2016; Salehi and Gholtash, 2011; Griffin, et al., 2009). No study examined the mediating role of job satisfaction on the relationship between emotional intelligence with job burnout. Therefore, it would be insightful to examine the indirect effect of emotional intelligence on job burnout through job satisfaction as a mediating variable. Thus, this study formulates the below hypothesis:

\section{Hypothesis 2:}

Job satisfaction mediates the relationship between emotional intelligence and job burnout.

Job satisfaction, defined as evaluative judgments employees hold toward their occupational duties (Meyer et al., 1993). Job satisfaction is important because it has strong implications for attendance, turnover, sabotage, job performance and the mental and physical health of employees (Miao, Humphrey and Qian, 2016). Sangganjanavanich and Balkin (2013) examined the correlation along with burnout and job satisfaction. The result came out to shed light on the importance of the link between job satisfaction and job burnout. Moreover, 
Khamisa, et al. (2015) conducted a research to investigate the relationship between different variables such as work stress, job satisfaction, job burnout and general health of nurses. The research showed a negative effect of job satisfaction on job burnout. Many of the studies such as (Hunsaker, et. al. 2015; Leung, et. al. 2015; Jasperse and Dungey 2014; Scanlan and Still 2013) emphasized importance of the relationship between job burnout and employee's satisfaction of various organizations.

Studies on nurses' job satisfaction in different countries revealed that job satisfaction is usually moderate or low in nursing profession (Akgöz et al. 2005; Asegid, Belachew and Yimam, 2014; Sabanciogullari and Dogan, 2015; Yilmaze, 2013). In addition, researchers explored some factors that lead to job dissatisfaction. These are low public appreciation for nursing profession or poor image of the profession, low wages, inadequate social opportunities, poor relationship with the management, lack of job security, inadequate involvement in decisionmaking processes, and inflexible working hours (Aiken, et al., 2013; El-Jardali, et al., 2009).

\section{Hypothesis 3:}

Job satisfaction is negatively related to job burnout.

\section{Research Design}

According to Creswell (2009), there are three common approaches that contribute to forming a research design including quantitative, qualitative and mixed-method. The quantitative approach was applied in obtaining the appropriate data to answer the questions of the study. In this study, an individual is considered as a unit of analysis. Only individuals who met the following criteria will be included in the analysis:

Above 21 - of both gender, all age groups, socio-economic status and educational status.

Only nurses who work in public hospitals in Gaza Strip.

A self-administrated questionnaire was selected as a research instrument to examine the relationship between the variables. According to Weinberger et al. (1996), Researchers get two advantages by using self-administrated questionnaire to collect the data from respondents. The first advantage is enabling the researcher to gather the required information from a large number of respondents within a specific time. The second advantage is reducing the errors that may have come from improper research design or misuse of some vocabulary.

\subsection{Measures}

A four-point Likert scale was used to determine the things, ranging from " 1 " as "highly disagree" to " 4 " as "highly agree". Researchers can get several gains from utilizing a four-point range such as boosting the validity of the inquiry, minimizing the neutral prejudice that occurs with a solution in the middle and cutting the possibility of answering without taking into consideration the things of measurement (Chomeya, 2010). All items utilized to determine emotional intelligence were adapted from Wong and Law (2002). A total number of 16 items; four items for each variable (self-emotion appraisal, others' emotion appraisal, use of emotion and regulation of emotion). This research made use of 12 items to gauge job satisfaction, the Minnesota Satisfaction Questionnaire (MSQ) developed by Weiss et al., (1967) was used to measure job satisfaction levels. Job burnout was measured by utilizing 9 items, which adapted from (Maslach and Leiter, 2008).

\subsection{Sample}

This study used non-probability sampling because it is impossible for the researcher to collect data from all nurses, as suggested by Saunders et al. (2009). The snowball-sampling technique was applied for two reasons. Firstly, it is impossible to obtain a list of all nurses contacts, the researcher could not have access to such data. Secondly, it is cheap, easy and subjects are always available (Etikan et al. 2016). According to Krejcie and Morgan (1970), 331 respondents is enough for a population of 2364 by using Krejcie and Morgan table. The researcher targeted more respondents as a margin of invalid and not returned respondents' questionnaire. The total number of planned respondents is 450 .

\section{Data Analysis}

This study uses Partial Least Squares Structural Equation Modelling (PLS-SEM) course modelling making use of Smart PLS 3.0 software using a two-step procedure to assess the study model (measurement model and structural model) as recommended by Henseler et al. (2009). Lots of research studies in the social scientific research domain used SmartPLS for statistical analysis, such as (Salem and Alanadoly 2020). 


\subsection{Demography of Respondents}

As mentioned before, 450 questionnaires have been distributed to the nurses in public hospital in Gaza Strip. However, only 381 usable questionnaires were returned to the researchers. Appendix 1 shows that the majority of participants were males (57\%), aged between 25 to 30 years old $(46.5 \%)$, bachelor's degree holders $(70.9 \%)$ and their monthly salary is below than NIS 2,000 (76.1\%).

\subsection{Assessment of Internal Consistency Reliability}

This study applied Cronbaches alpha and composite reliability (CR) checks to analyse the reliability of the internal consistency of the framework. As a trustworthy research tool, the worths of Cronbaches alpha and composite reliability must be at least 0.7 for each and every construct (Hair et al., 2016). The outcomes indicated that all the constructs have an acceptable level of internal consistency reliability, as illustrated in Table 1.

Table 1. Internal Consistency Reliability

\begin{tabular}{|l|l|l|}
\hline Construct & Cronbach ${ }^{\text {ee }}$ Alpha & Composite Reliability \\
\hline Other's emotion appraisal & 0.773 & 0.855 \\
\hline Regulation of emotion & 0.814 & 0.876 \\
\hline Self-emotion appraisal & 0.804 & 0.872 \\
\hline Use of emotion & 0.858 & 0.904 \\
\hline Job Satisfaction & 0.936 & 0.945 \\
\hline Job Burnout & 0.849 & 0.910 \\
\hline
\end{tabular}

\subsection{Assessment of Convergent and Discriminant Validity}

This study assessed the convergent validity by examining the average variance extracted (AVE) value. The satisfactory level of (AVE) is 0.5 or more for each construct (Hair et al., 2016; Salem and Salem 2019). The AVE of each construct in this study ranges from 0.588 to 0.882 , which is considered higher than the recommended value. On the other hand, the Cross-Loading Output test was applied to assess discriminant validity. The results showed that the indicatorse loadings in the original variable are higher than all other loadings. Therefore, the measurement model of this study has a satisfactory level of convergent and discriminant validity, as illustrated in Appendix 2.

\subsection{Hypothesis Testing}

The bootstrapping procedure was applied with a number of 5,000 bootstrap samples and 381 cases to generate tstatistics for all paths in order to test the significant level. The following sections explain the results related to each hypothesis.

The findings demonstrate that EI has a positive effect on JB $(\beta=0.174, \mathrm{t}=3.621, \mathrm{p}=0.01)$. Hence, H1a is accepted. The findings demonstrate that EI has a negative significant impact on JB $(\beta=-0.198, t=4.432, p=$ $0.01)$. Hence, $\mathrm{H} 1 \mathrm{~b}$ is accepted.

Table 2 presents the path coefficients of the relationship between EI as an independent variable with JS as a mediator associated with its significance and the relationship between the mediator (JS) with dependent variable (JB) associated with its significance. Furthermore, it shows the path coefficients of the total effect and indirect effect of the relationship between EI, JS and JB associated with their significance. The findings show that EI has a positive significant effect on JS $(\beta=0.174, \mathrm{t}=3.621, \mathrm{p}=0.01)$. Moreover, the path coefficient of the relationship between JS and JB is significant $(\beta=-0.184, \mathrm{t}=3.573, \mathrm{p}=0.01)$. Furthermore, the path coefficient of the direct relationship between EI and JB is also significant $(\beta=-0.198, \mathrm{t}=4.432, \mathrm{p}=0.01)$. Hence, the relationship between EI and JB is partially mediated by JS and $\mathrm{H} 2$ is accepted. 
Table 2. Path coefficients of EI a

\begin{tabular}{|c|c|c|c|c|c|c|c|c|c|c|}
\hline \multirow[t]{2}{*}{ Mediation } & \multicolumn{2}{|c|}{ IV to Mediator } & \multicolumn{2}{|c|}{$\begin{array}{l}\text { Mediator to } \\
\text { DV }\end{array}$} & \multicolumn{2}{|c|}{ Direct Effect } & \multirow{2}{*}{$\begin{array}{l}\text { Total } \\
\text { Effect } \\
(\beta)\end{array}$} & \multirow[t]{2}{*}{$\begin{array}{l}\text { Indirect } \\
\text { Effect }(\beta)\end{array}$} & \multirow{2}{*}{$\begin{array}{l}\text { Indirect } \\
\text { Effect } \\
\text { Sig. }\end{array}$} & \multirow[t]{2}{*}{$\begin{array}{l}\text { Partial/ } \\
\text { Full }\end{array}$} \\
\hline & $(\beta)$ & Sig. & $(\beta)$ & Sig. & $(\beta)$ & Sig. & & & & \\
\hline EI->JS->JB & 0.174 & 0.01 & -0.184 & $\begin{array}{l}0.0 \\
1\end{array}$ & -0.198 & 0.01 & -0.230 & -0.032 & 0.01 & Partial \\
\hline
\end{tabular}

Table 3 presents the path coefficient and significance level findings of the relationship between JS and JB. The findings demonstrate that JS has a negative significant impact on JB $(\beta=-0.184, t=3.573, p=0.01)$. Hence, H3 is accepted.

Table 3. Path Coefficient

\begin{tabular}{|l|l|l|l|l|l|}
\hline Hypothesis & Relation & Significance & Sign & $\begin{array}{l}\text { Path Coefficient } \\
(\beta)\end{array}$ & T Statistics \\
\hline H6 & JS-> JB & 0.01 & - & 0.184 & 3.573 \\
\hline
\end{tabular}

\section{Discussion}

emotional intelligence defined as "a set of interrelated abilities at the interface of emotion and cognition, including perceiving, understanding, using, and managing emotions" (Lopes 2016, p. 316). This study used Wong and Law (2002) sixteen-item scale to measure emotional intelligence. The findings showed that emotional intelligence has a positive impact on job satisfaction, which match the findings of previous studies that examined the relationship between emotional intelligence and job satisfaction (Liu 2016; Soleimani and Einolahzadeh 2017; Wen et al. 2019).

Liu (2016) study used 33-item scale developed by Schutte et al. (1998) to examine emotional intelligence and they found that the emotional intelligence of Chinese employees from two middle-sized state-owned enterprises has a positive effect on their level of job satisfaction. Moreover, Soleimani and Einolahzadeh (2017) study proved that the level of job satisfaction of the staff of a company in Tehran in Iran is positively affected by emotional intelligence. In the same context, Wen et al. (2019) study used Wong and Law (2002) sixteen-item scale to measure emotional intelligence and they also confirmed that emotional intelligence of the hotel employees in Guangzhou and Shenzhen in China has a positive impact on job satisfaction.

\subsection{Contribution and Implications}

This study has made contributions to research by examining the impact of emotional intelligence on job satisfaction and job burnout. Furthermore, this study examined the mediating effect of job satisfaction on the relationship between emotional intelligence and job burnout in healthcare industry of Gaza Strip in Palestine. Many studies have been done to examine the effect of emotional intelligence on job satisfaction (Liu 2016; Soleimani and Einolahzadeh 2017; Wen et al. 2019) and the effect of job satisfaction on job burnout (Ali and Ali 2014; Salehi and Gholtash 2011; Vousiopoulos et al. 2019) in different industries. However, no study examined the mediating effect of job satisfaction on the relationship between emotional intelligence and job burnout.

This study applied the affective theory developed by Heise (1979) as the main theoretical foundation to examine the effect of emotional intelligence on job satisfaction. The findings confirmed that emotional intelligence has a positive effect on job satisfaction, which considered compatible with previous studies that indicated there is a positive relationship between emotional intelligence and job satisfaction (Liu 2016; Soleimani and Einolahzadeh 2017; Wen et al. 2019). On the other hand, the findings showed that emotional intelligence has a negative impact on job burnout, which considered consistent with previous studies that indicated there is a negative relationship between emotional intelligence and job burnout (Ayala and Keren 2020; Barari and Jamshidi 2015; Iqbal and Abbasi 2013). Furthermore, the findings of mediation analysis showed that job satisfaction partially mediates the relationship between all emotional intelligence and job burnout. 
This study contributes to the emotional intelligence literature by presenting the different dimensions of emotional intelligence, discussing affective theory, which was developed by Heise (1979), demonstrating the direct effect of emotional intelligence on job satisfaction and job burnout and being the first study that examined the mediating effect of job satisfaction on the relationship between emotional intelligence and job burnout of the nurses of the largest three hospitals in Gaza strip in Palestine.

\subsection{Limitation and Future Research}

First of all, the population of this research study was limited to the nurses in public hospitals in Gaza Strip. Future study needs to check out the impact of emotional intelligence on job satisfaction and job burnout in various other industries. Second, this research study took a look at the impact of emotional intelligence on job satisfaction and job burnout only. The future research study is recommended to focus extra on checking out the influence of emotional intelligence on other job outcomes such as employee performance and intention to quit.

This study made use of the only quantitative method in the data collection procedure. Therefore, future study is advised to combine qualitative and quantitative techniques.

\subsection{Conclusion}

The primary objective of this research study is to take a look at the effect of emotional intelligence of the nurses in public hospitals in Gaza on job satisfaction and job burnout and the mediating role of job satisfaction in the connection between emotional intelligence and job burnout. The outcomes of Smart PLS course model exposed that emotional intelligence has a positive impact on job satisfaction and job burnout. On the other hand, findings validated that job satisfaction fully mediates the connection between emotional intelligence and job burnout.

\section{References:}

Arvey, R.D., Renz, G.L. \& Watson, T.W. (1998), "Emotionality and Job Performance: Implications for Personnel Selection", Research in Personnel and Human Resources Management, 16, 103-147.

Asvio, N., Yamin, M. \& Risnita. (2019), "Influence of Leadership Style, Emotional Intelligence and Job Satisfaction Toward Organizational Commitment (Survey At SMA Muhammadiyah South Sumatera)", International Journal of Scientific \& Technology Research, 8(8), 1360-1376.

Bar-On, R. (2006), “The Bar-On Model of Emotional-Social Intelligence (ESI)”, Psicothema, 18, 13-25.

Chomeya, R. (2010), “Quality of Psychology Test between Likert scale 5 and 6 Points", Journal of Social Sciences, 6(3), 399-403.

Cokluk, O. (2000), Burnout in Organizations. In C. Elma, \& K. Demir eds. Contemporary Approaches in Management: Applications and Issues. Ankara: Ani Publishing, pp. 109-133

Creswell, J.W. (2009), Research Design: Qualitative, Quantitative and Mixed Methods Approaches. Sage, Thousand Oaks CA.

Daus, C.S. \& Ashkanasy, N.M. (2003), "Will the Real Emotional Intelligence Please Stand Up? On Deconstructing the Emotional Intelligence "Debate"", The Industrial-Organizational Psychologist, 41(2), 69-72.

Davenport, T.H. (2013), Process innovation: Reengineering work through information technology. Harvard Business Press.

Etikan, I., Musa, S.A. \& Alkassim, R.S. (2016), "Comparison of Convenience Sampling and Purposive Sampling”, American Journal of Theoretical and Applied Statistics, 5(1), 1-4.

Fernandez-Berrocal, P. \& Ruiz, D. (2008), "Emotional Intelligence in Education”, Electronic Journal of Research in Education Psychology, 6(2), 421-436.

Freudenberger, H. J. (1974), “Staff Burnout”, Journal of Social Issues, 30, 159-165.

Gardner, H. (1983), Frames of mind: The theory of multiple intelligences. New York, NY: Basic Books. 
Gholipour, S.A. \& Einolahzadeh, H. (2017), The Mediating Effect of Leader-Member Exchange in Relationship with Emotional Intelligence, Job Satisfaction, and Turnover Intention”, Cogent Business \& Management, 4(1), $1-14$.

Goleman, D. (1995), Emotional intelligence. New York: Bantam.

Goleman, D. (1998), Working with Emotional Intelligence. New York, NY: Bantam Books

Griffin, M.L., Hogan, N.L., Lambert, E.G., Tucker-Gail, K.A. \& Baker, D.N. (2010), "Job Involvement, Job Stress, Job Satisfaction, and Organizational Commitment and The Burnout of Correctional Staff', Criminal Justice and Behavior, 37(2), 239-255.

Henseler, J., Ringle, C.M. \& Sinkovics, R.R. (2009), The Use of Partial Least Squares Path Modeling in International Marketing. In Sinkovics, R.R. and Ghauri, P.N. (Eds.), Advances in International Marketing, Bingley: Emerald, pp. 20: 277-320.

Hunsaker, S., Chen, Hsiu-C., Maughan, D. \& Heaston, S. (2015), "Factors that Influence the Development of Compassion Fatigue Burnout, and Compassion Satisfaction in Emergency Department Nurses", Journal of Nursing Scholarship, 47(2), 186-194.

Iqbal, F. \& Abbasi, F. (2013), "Relationship between Emotional Intelligence and Job Burnout among Universities Professors", Asian Journal of Social Sciences \& Humanities, 2(2), 219-229.

Jasperse, M., Herst, P. \& Dungey, G. (2014), "Evaluating Stress, Burnout and Job Satisfaction in New Zealand Radiation Oncology Departments", European Journal of Cancer Care, 23, 82-88.

Khamisa, N., Oldenburg, B., Peltzer, K. \& Ilic, D. (2015), "Work Related Stress, Burnout, Job Satisfaction and General Health of Nurses", International Journal of Environmental Research and Public Health, 12(1), 652-666.

Krejcie, R.V. \& Morgan, D.W. (1970), “Determining Sample Size for Research Activities”, Educational and Psychological Measurement, 30, 607-610.

Leung J., Rioseco P. \& Munro, P. (2015), "Stress, Satisfaction and Burnout amongst Australian and New Zealand Radiation Oncologists", Journal of Medical Imaging and Radiation Oncology, 59(1), 115-124.

Liu, D. (2016), "Mediating Effect of Social Support Between the Emotional Intelligence and Job Satisfaction of Chinese Employees", Current Psychology, 37(1), 366-372.

Locke, E.A. (1976), The Nature and Causes of Job Satisfaction. In M.D. Dunnette ed. Handbook of Industrial and Organizational Psychology. Chicago: Rand McNally. pp. 1297-1349.

Maslach, C. \& Leiter, M.P. (2008), "Early Predictors of Job Burnout and Engagement", Journal of Applied Psychology, 93(3), 498-512.

Maslach, C. (1981), "The Measurement of Experienced Burnout”, Journal of Organizational Behavior, 2(2), 99113.

Mayer, J.D. \& Salovey, P. (1997), What is Emotional Intelligence? In P. Salovey, \& D.J. Sluyter eds. Emotional Development and Emotional Intelligence. New York: Basic Books. pp. 3-31.

Mayer, J.D., Salovey, P. \& Caruso, D. (2000), "Emotional Intelligence Meets the Traditional Standards for Intelligence", Intelligence, 27(4), 267-298.

Meyer, J.P., Allen, N.J. \& Smith, C.A. (1993), "Commitment to Organizations and Occupations: Extension and Test of A Three-Component Conceptualization”, Journal of Applied Psychology, 78(4), 538-551.

Miao, C., Humphrey, R. H. \& Qian, S. (2016), “A Meta-Analysis of Emotional Intelligence and Work Attitudes", Journal of Occupational and Organizational Psychology, 90(2), 177-202.

Ministry of Health, Gaza. (2019). Annual Report.

Nabirye, R.C., Brown, K.C., Pryor, E.R. \& Maples, E.H. (2011), “Occupational Stress, Job Satisfaction and Job Performance Among Hospital Nurses in Kampala, Uganda", Journal of Nursing Management, 19(6), 760-768. 
Peng, J., Li, D., Zhang, Z., Tian, Y., Miao, D., Xiao, W. \& Zhang, J. (2016), "How Can Core Self-Evaluations Influence Job Burnout? The Key Roles of Organizational Commitment and Job Satisfaction", Journal of Health Psychology, 21(1), 50-59.

Petrides, K.V. (2011), Ability and Trait Emotional Intelligence. In T. Chamorro-Premuzic, S.V. Stumm, \& A. Furnham eds. Handbook of Individual Differences. Blackwell Publishing Ltd. pp.656-678.

Preksha, S. \& Maheshwari, S. (2018), "Managing Stress in Nursing Profession”, International Journal of Current Research, 10(5), 69740-69744.

Putnam, L.L. \& Mumby, D.K. (1993), Organizations, Emotion and the Myth of Rationality. In S. Fineman, ed. Emotion in Organizations. London: Sage. pp. 36-57.

Salehi, M. \& Gholtash, A. (2011), "The Relationship between Job Satisfaction, Job Burnout and Organizational Commitment with the Organizational Citizenship Behavior among Members of Faculty in The Islamic Azad University-First District Branches, in Order to Provide the Appropriate Model", Procedia-Social and Behavioral Sciences, 15, 306-310

Salem, S.F. \& Alanadoly, A.B. (2020), "Personality Traits and Social Media as Drivers of Word-Of-Mouth towards Sustainable Fashion", Journal of Fashion Marketing and Management.

Salmi, S. \& Kinnunen, T. (2015), “Nonverbal Communication: Unspoken Messages”, Unpublished dissertation. Jamk University of Applied Sciences.

Salovey, P. \& Mayer, J.D. (1990), “Emotional Intelligence”, Imagination, Cognition, and Personality, 9, 185211.

Sangganjanavanich, V. \& Balkin, R. (2013), "Burnout and Job Satisfaction among Counselor Educators", Journal of Humanistic Counseling, 52, 67-79.

Saunders, M., Lewis, P. \& Thornhill, A. (2009), Research methods for business students 5th ed. Pearson Education Limited, England.

Scanlan, J. \& Still, M. (2013), "Job Satisfaction, Burnout and Turnover Intention in Occupational Therapists Working in Mental Health", Australian Occupational Therapy Journal, 60, 310-318.

Sy, T., Tram, S. \& O’Hara, L. (2006), "Relation of Employee and Manager Emotional Intelligence to Job Satisfaction and Performance", Journal of Vocational Behavior, 68, 461-473.

Tagoe, T. \& Quarshie, E.N. (2016), “The Relationship between Emotional Intelligence and Job Satisfaction among Nurses in Accra", Nursing Open, 4(2), 84-89.

Thorndike, E.L. (1920), “Intelligence and Its Uses”, Harper's Magazine, 140, 227-235.

Weinberger, M., Oddone, E.Z., Samsa, G.P. \& Landsman, P.B. (1996), “Are Health-Related Quality-Of-Life Measures Affected by The Mode of Administration?”, Journal of Clinical Epidemiology, 49, 135-140.

Weiss, H.M. (2002), "Deconstructing Job Satisfaction: Separating Evaluations, Beliefs and Affective Experiences", Human Resource Management Review, 12, 173-194.

Zhang, Y.C., Xu, S., Jin, J.F. \& Ford, M.T. (2018), "The Within and Cross Domain Effects of Work-Family Enrichment: A Meta-Analysis", Journal of Vocational behavior, 104: 210-227. 